\title{
Sexual Health: sexual knowledge, behavior and social determinants in the students of the University of Porto - a cross sectional study
}

Raquel Araujo Almeida ( $\sim$ raquel_araujo_almeida@hotmail.com )

Faculty of Medicine, University of Porto https://orcid.org/0000-0003-4030-3391

Paulo Santos

Faculty of Medicine of the University of orto

Research article

Keywords: sexual health, sex education, sexual behavior, social determinants of health

Posted Date: July 5th, 2019

DOl: https://doi.org/10.21203/rs.2.11037/v1

License: (c) (i) This work is licensed under a Creative Commons Attribution 4.0 International License.

Read Full License 


\section{Abstract}

Background: When considering sexual health, the youth is a particularly susceptible group. In Portugal, structured sexual education is available, however, 23.5\% of new HIV cases in 2017 occurred in a population aged 15-29 years old. We attempt to understand the range of sexual health knowledge in youth, along with sexual behaviors and their influencing characteristics. Our main aim is to describe the relation between knowledge and sexual health-related behavior. Methods: This observational crosssectional study involved an online questionnaire covering different areas of sexual health applied to students from the University of Porto, Portugal. This was used to create a knowledge and behavior score. Socio-demographic characteristics were used to examine associations with the scores. The relationship between the scores was assessed with Pearson's bivariate correlation. Results: Out of 1815 questionnaires, 988 (54\%) were validated. The mean score for knowledge was 3.74 out of $5(95 \%$ confidence intervals [Cl]: 3.69-3.77) and 3.4 out of 5 (95\% Cl: 3.38-3.44) for the behavior score. The knowledge score was influenced significantly by age and whether students frequented degrees in healthrelated studies. Only gender influenced sexual behavior. The correlation between knowledge and behavior was statistically significant with $p<0.01$ and a coefficient of +0.127 . Conclusion/Discussion: Knowledge is an essential but insufficient determinant for health literacy. We urge the development of a sexual health prevention/education program which considers the interacting factors and motivates participants to integrate the assimilated information on a daily basis.

\section{Background}

Sexual health is defined as a state of physical, emotional, mental and social well-being concerning sexuality, not merely the absence of disease, dysfunction or infirmity. This is a broad topic which includes sexuality and relationships, the respect for sexual rights, pleasure and safeness of sexual experiences, and the freedom to choose without coercion, discrimination or violence. Sexuality is intrinsic to human beings, encompassing not only the reproductive processes, but also sex and relationship roles, sexual orientation and gender identities, eroticism, pleasure and intimacy. The interaction of biological, psychological, social, economic, political, cultural, legal, historical, religious and spiritual factors is fundamental in understanding human sexuality. [1]

[1] However, sexually transmitted infections (STI) and unwanted pregnancies are relevant restraints, functioning as threats that may limit the freedom of options regarding behaviors and lifestyles. The majority of risk factors are well-known and most of them are preventable: young age, recent change of sexual partner, increased number of sexual partners, young age at first sexual intercourse, previous history of STI, inconsistent use of condoms, and difficulty in accessing health services.[2]

Literacy is the key for an effective preventive approach. [3] Education using trained providers intends to improve knowledge and attitudes about sexual health, particularly in most vulnerable core groups, such as adolescents and emerging adults. [4] Nevertheless, education is only fully effective if it is complemented by the shaping of competences leading towards better health behaviors. The aim of 
health education is an informed population, empowered to better decisions in their own lifestyle options $[3,5]$ and thus positively remodeling their own health. [6] Sexual education programs showed to have positive effects, leading to an increase in knowledge and a reduction of risk behaviors and STIs. [7] Furthermore, they also provide access to family planning and medical assistance, in an environment of trust and confidence. [8]

Young people are particularly vulnerable to both unwanted pregnancy and STIs: about one third of the 340 million yearly STI transmitted worldwide affect people under 25 years old. Indeed, over half of new infections by the Human Immunodeficiency Virus (HIV) occur between 15 and 25 years of age [9] and one-third of gonorrhea and chlamydia infections occur between 20 and 24 years. [10] College students are more likely to demonstrate high risk behaviors: $11 \%$ of sexually active college students do not use any form of effective birth control and $29 \%$ report not using condoms consistently. [10]

In Portugal, sexual education is inserted at all levels of school curricula since 2009 (1984 parliament law $n^{\circ} .3 / 84$ of the 24 of March). Assuming that all students were enrolled in these programs, it should be expected that this population would have better behaviors, fewer unwanted pregnancies, fewer abortions and fewer STIs. In the last decade in Portugal, there has been a 50\% reduction of births to mothers below the age of 20 years, along with a 15\% reduction in legal abortions, however, the total birth rate declined by roughly $25 \%$. The incidence of new HIV infections reduced in the same time period, but the incidence and absolute number of syphilis and gonorrheal infections increased. In 2017, 23.5\% out of the 886 new HIV cases occurred in the youth aged 15-29 years and about one third of the 15959 abortions realized occurred in females under the age of 25 in Portugal. [11]

Although information and knowledge is provided, the acquisition of attitudes leading to sexual health competences is not guaranteed. Unfortunately, in this manner health literacy is not achieved, [8] and the actual impact of sexual educational programs is largely unknown. [12]

The aim of this study is to characterize the relationship between knowledge and behavior related to sexual health, while understanding the influence of individual characteristics on sexuality and its impact on behavior.

\section{Methods}

We conducted a cross-sectional study using students enrolled in the University of Porto in Portugal.

This university consists of 14 faculties, hosting over 20000 students in a total of 34 bachelor's degrees and 18 integrated master's degrees, and about 10000 students in postgraduate education.

All Portuguese speaking students aged over 16 years attending a pre-graduation course at the University of Porto were eligible for participation.

A minimum sample size of 1492 participants was estimated, assuming an unknown distribution of the main outcome and a maximum error of $2.5 \%$, for a $95 \%$ confidence interval. 
The data collection occurred from March 2018 to May 2018. Invitations to participate were sent every three weeks via the institutional email system over four different occasions until the predicted sample size was reached.

The applied questionnaire was based on those used by Reis et al [13] and Nobre et al, [14] previously validated for Portuguese utilization. Questions intended to characterize the students' behaviors, knowledge, attitudes, intentions, comfort and competences about sexual health, as well as their interest and perceptions about sexual education. We also evaluated social and demographic variables including age, gender, studying in a health-related course, socioeconomic characterization by Graffar Index, residence type, sexual orientation, lifestyle habits and spirituality. Spirituality is a wide concept influencing participants' points of view regarding sexuality and sexual experiences. [1] Questions evaluating knowledge were classified as dichotomic true or false variables. A five-point Likert scale was used to characterize behavior. Spirituality was checked in four categories: atheist, believing in a personal God, belief in a living force/spirit and no formal opinion. All items with incomplete responses were treated as missing data.

Questions were categorized as knowledge-related and behavior-related, according to the characteristics of effective sexual health education programs described by Kirby et al for HIV/AIDS interventions. [15]

Knowledge about sexuality focused on four areas: general knowledge, oral contraception, condom use and HIV/AIDS, accounting for a total 30-item scale. Correct answers were worth 2 points, partially correct answers were awarded 1 point, while incorrect or unknown answers were not awarded any points. A maximum of 60 points was transformed into a $0-5$ classification by simple division by 12 , with 5 as the highest score and 0 as the lowest score.

Students' sexual behavior was assessed by 20 different questions considering the use of contraception, the frequency of occasional partners, sex under the influence of alcohol or drugs and an individual history of STI or unwanted pregnancy. Answers were classified between 0-4 points using the Likert scale with a maximum of 80 points, transformed by simple division by 16 into a scale classifying behavior between 0 5.

The study protocol was assessed and approved by Ethical Committee of Hospital de São João / Faculty of Medicine of University of Porto. The conduction of research followed the principles of Helsinki Declaration and the Oviedo Convention regarding the protection of human rights in the biomedical investigation, as per Portuguese Law. Although it was distributed by e-mail, the first page of the web-form included information for participants and asked for their explicit consent, allowing refusal with an automatic dropout from the study.

We used descriptive and inferential statistics. Knowledge and behavior scores were dichotomized in high or low, according to the median (3.83 and 3.75, respectively). Logistic regression was used to check the association with univariate analysis using both the knowledge and behavior scores. Other variables were dichotomized taking into account the primary representation in the population studied: heterosexuality vs 
other, spirituality (believing in God or a living force/spirit) vs non-spirituality, mean age (younger or older than 21), and socioeconomic classification by Graffar Index where the first category corresponds to the upper class and the fifth category to the lower class. The test of Kolmogorov-Smirnov test was used to check for normal distribution. Multiple logistic regression was performed to analyze eventual confounding and interaction. The relationship between the scores of knowledge and behavior was assessed by Pearson's bivariate correlation. We accepted an alpha error of 0.05 . Data were registered in a Microsoft Office Excel $2013 \AA$ database and analyzed using IBM SPSS Statistics ${ }^{\circledR}$, version 25.0 (IBM Corp., Armonk, NY, USA $\left.{ }^{\circledR}\right)$.

\section{Results}

Overall, 1815 participants answered the questionnaire, of which 1131 responses were considered valid (62.3\%). Incomplete questionnaires were the main reason for considering these invalid. As expected by the demography of University of Porto, participants were mainly Portuguese, living in an urban area, with a mean age of $21.6( \pm 3.0)$ years old. Females represented $73.3 \%$ of the responses. Most students were attending a bachelor's degree (57.6\%), 54.9\% in health-related courses. Upper middle and upper socioeconomic class represented $76.5 \%$ of students. Less than half of the population declared some kind of spiritual commitment, such as believing in a personal God or in a living force/spirit (48.5\%). Heterosexuality was the most prevalent sexual orientation (77.0\%) in a population where $91.3 \%$ of students were sexually active and $74.3 \%$ had attended at least one sexual education program.

Table 1 shows the demographic characteristics of our sample.

Overall, 988 questionnaires (87.4\%) were completely answered allowing to calculate knowledge and behavior scores.

The mean knowledge score was 3.74 out of 5.00 (95\% Cl: 3.69-3.77), varying from 1.00 to 4.83 points. In 880 valid answers, the average behavior score was 3.41 out of 5.00 ( $95 \% \mathrm{Cl}: 3.38-3.44)$, varying from 0.88 to 4.55 points.

Knowledge and behavior scores were dichotomized as high or low according to the median of distribution of each score. Figure 1 shows the association with age, gender, health-related course of studies, spirituality, socioeconomic classification, habitational zone and sexual orientation for both scores.

In univariate analysis, knowledge is lower in those under 21 years of age $(\mathrm{OR}=0.54 ; 95 \% \mathrm{Cl}: 0.42-0.70)$ and higher in those attending health-related courses (OR=3.28; $95 \% \mathrm{Cl}: 2.52-4.26)$. Only gender seems to play a significant role in the behavior adopted by the students, with males presenting higher risk behaviors than females (OR=1.62; 95\%Cl:1.23-2.32).

Multivariate analysis, after adjusting for the factors shown in Figure 1, confirmed the previous findings; age (namely students younger than 21 years) was associated with lower knowledge scores $(O R=0.56$; 
95\%Cl:0.43-0.74; $p<0,001)$, while attending a health-related course was associated to a higher knowledge score (OR=3.27; 95\% Cl:2.50-4.27; $\mathrm{p}<0,001)$, and females presented better behavior scores $(\mathrm{OR}=1.58$; 95\%Cl:1.10-2.28; $p<0.05)$.

Knowledge and behavior scores were intrinsically related (Figure 2): a higher knowledge score was associated with better behavior scores, although the correlation found was weak $(\rho=0.127 ; p<0.01)$.

\section{Discussion}

The relationship found between knowledge regarding sexual issues and behavior in university students is significant, although weak. We found that students presented satisfactory knowledge scores (3.74 out of 5.00), meaning that sexual education programs succeeded in transmitting information, but these appear to fail at enabling students to apply this knowledge on a daily basis. Under the concept of health literacy, a stronger association between knowledge and behaviour in sexual health could be expected. Indeed, a higher knowledge rate should be translated itself in a practice of safer sex [16, 17], although this type of knowledge does not necessarily reflect a higher level of health literacy, as described by Nutbeam (2000) [18].

Our results are consistent with previous studies. Kirby (2010) showed that inconsistent use of condoms and contraceptives is not directly related to a scarcity of knowledge. [19] Weinstein (2008) even found that greater knowledge was associated with less consistent condom use. [20] This phenomenon could be justified by the fact that having sexual risk behaviors are related to feelings of threat. Threat here refers to an eventual behaviour perceived as risky or which may thus lead to an active demand for information. In this model, risky experiences are the motive for improving information, inverting the cause-effect relationship. Conversely, the practice of safe sex and the consequent low risk perception may justify some indifference to the need to keep informed, thus conditioning less knowledge. [21] This interactive pattern emphasizes that knowledge is an important, but insufficient, determinant to adequate health literacy. The link between knowledge and behavior relies on working on the intrinsic individual characteristics, including their personal beliefs as well as perceived benefits, barriers and efficacy of education. [22] Changing behaviors must not only depend on the general threat of an undesired pregnancy or contracting an infectious illness, but also through understanding these individual characteristics and their interactions. This may lead to a real possibility to integrate safer practices into a daily routine. [16] Training the youth to become peer educators is a feasible strategy to reach the desired goals through the creation of a confidential, informal and judgmental environment while allowing the shared exploration of the different dimensions of sexual health.

Additionally, we identified population characteristics influencing knowledge and behavior. Knowledge scores were higher in older students and in those attending a health-related course. Only female gender was shown to be associated with better behavior. The behavior of students undertaking health-related courses may be considered paradoxical, as the behavior demonstrated did not match the increased information available to these students. Frank et al (2008), in the USA, [23] demonstrated a similar level 
of knowledge in medical students, however, Fayers (2003) [24] and Warner (2018) [25] found no relation between better information and better behavior patterns. As may be expected, older students collect more information through lifelong continuous learning, [26] which consequently leads to a greater knowledge base. In this specific context, the admission to college and the perception of autonomy and independence are potential conditioners of better behaviors. [9] Late adolescence and emerging adulthood is a phase of experimentation in several dimensions, including sexuality. $[27,28]$ Younger ages are generally related to higher rates of ISTs and to risky behaviors, such as multiple sexual partners, sexual intercourse under alcohol or drugs consumption, [29] and the perception of being free of disease regardless of the risks. [30] An apparent lack of improvement with age in college students may be justified as a functional feature related to financial dependence and student status, which may extend risk behaviors until graduation. Although not significant, we noticed a tendency for better behavior with higher socioeconomic status, in accordance with the literature. [30-33]

Gender is the only factor significantly associated with sexual behavior. As described in other studies, [7, 9, 13, 34-36] we found males to be more prone to engage in sexual risk-taking behaviors, based on a balance between evolutionary psychology and social role perspectives. Evolutionary theory defends that this difference is largely innate and biologically-based due to the different mating strategies of men and women. [37, 38] In contrast, social roles are mostly acquired and resultant from both formal and informal education. [39] More recently, a holistic approach for gender differences takes in account both of these dimensions. [7] It proposes that gender-typed behavior is a product of the respective reproductive activities and physical attributes in conjunction with the organizational demands of societies. [7] Although societies are evolving to be more permissive, a negative connotation towards sexuality is still enrooted in some women, perpetuating the social double-standards by which judgmental-free sexuality preferentially relates to men. [40] Women are expected to engage in long-lasting relationships, while men are expected to value sexual experiences. [41] Males are not prejudiced when engaging in sexual interactions and masturbation, while females may be conflicted about embodied sexual feelings. [42]

Religion and spiritually are usually significant factors in in the experience of sexuality. [23, 30, 34] We assessed this by asking participants their spiritual affiliation. In Portugal, religious questions are restricted for research purposes, which limits the specific characterization of religious denominations. No relationship was found in our population. The impact of spirituality is seen mainly at the beginning of sexual life. Additionally, the strength of spiritual conviction is not equivalent to the concept of participation and religious affiliation, and this analysis should also be different. [43]

Unlike Laura Kann et al (2018), in United States, [44] we found no evidence of the influence of sexual orientation over both knowledge and sexual related behaviors. The Youth Risk Behavior Surveillance United States, 2017 pointed riskier behaviors in lesbians, gays, bisexuals and transgenders in comparison with heterosexuals. The scholar context of our population, linked to safer practices, [12] may influence this outcome. 
Our results must be interpreted while considering the limitations of this study. Firstly, the sample was limited to active students of the University of Porto. These students are part of a higher educated population and the results might be influenced through this social context. Dropping out of school appears to be associated with increased sexual risk-taking behavior [12] such as a lack of consistent use of contraception [45] or unwanted pregnancy. [46] Secondly, these students were asked to participate through dynamic emails. We cannot guarantee that all emails were updated, or that all students have access to institutional emails. Furthermore, the participation in the study was optional. It is likely that students who participated in this questionnaire may present different characteristics to those who did not participate. These students may have a special interest in sexual health, potentially overestimating their level of knowledge and behaviors. Additionally, the questions used, although based on validated and language-adapted questionnaires, may have been misunderstood or misinterpreted. Finally, even though the questions were reliable and verified [15], the composed comparison scores were not, which could insert an error in the statistical analysis. As far as we know, there is no gold standard to evaluate knowledge and sexual behaviors in this population, although numerous scales have been previously used. $[20,21,47]$

In conclusion, although we succeeded in transmitting information to a college population, we are still far from transforming this knowledge into attitudes and skills leading towards better behaviors. This urges us to change the paradigm and to implement strategies to empower emerging adults to put into practice the knowledge acquired, thereby creating a healthy sexual environment. Knowledge, although not sufficient, is a necessary condition for better literacy, and strategic goals must be adapted to the current situation for real improvement of sexual-related behaviors, favoring a sexuality which is healthy, safe, responsible and satisfactory.

Even though it is not possible to extrapolate our results to non-college students, we believe that similar patterns may be present in other populations. As health-care providers, we should reflect on what these results may mean not only for our patients, but also in our personal lives.

Indeed, do we practice what we preach?

\section{Declarations}

\section{Ethics approval and consent to participate}

The study protocol was assessed and approved by Ethical Committee of Hospital de São João/ Faculty of Medicine of University of Porto. The conduction of research followed the principles of Helsinki Declaration and the Oviedo Convention concerning the protection of human rights in biomedical research, as according to Portuguese Law.

\section{Consent for publication}


The first page of the web-form included information for participants and asked for their explicit consent, allowing refusal with an automatic dropout from the study.

\section{Availability of data and materials}

The datasets used and/or analyzed during the current study are available from the corresponding author upon reasonable request.

\section{Competing Interests}

The authors declare that they have no competing interests

\section{Funding}

This article was supported by National Funds through FCT - Fundação para a Ciência e a Tecnologia within CINTESIS, R\&D Unit (reference UID/IC/4255/2019). The support is associated with the possible publishing of the article and has not been applied in any other stage of production of this article.

\section{Authors contributions:}

All authors, Raquel Almeida and Paulo Santos, made substantial contributions to the conception or design of the work; or the acquisition, analysis, or interpretation of data for the work; AND

- Drafting the work or revising it critically for important intellectual content; AND

- Final approval of the version to be published; AND

- Agreement to be accountable for all aspects of the work in ensuring that questions related to the accuracy or integrity of any part of the work are appropriately investigated and resolved.

\section{Acknowledgements:}

Not applicable.

\section{References}

1. World Health Organization: Sexual health and its linkages to reproductive health: an operational approach. In. Geneve: World Health Organization; 2017.

2. Fethers KA, Fairley CK, Hocking JS, Gurrin LC, Bradshaw CS: Sexual Risk Factors and Bacterial Vaginosis: A Systematic Review and Meta-Analysis. Clinical Infectious Diseases 2008, 47(11):14261435.

3. Santos P, Sá L, Couto L, Hespanhol A: Health literacy as a key for effective preventive medicine. Cogent Social Sciences 2017, 3(1):1407522. 
4. Douglas K: The impact of sexual education on the sexual behaviour of young people. In. Edited by United Nations Department of Economic and Social Affairs Population Division, vol. Expert Paper No. 2011/12: World Health Organization; 2012.

5. Medicine lo: Health Literacy: A Prescription to End Confusion. Washington, DC: The National Academies Press; 2004.

6. Division of Health Promotion Education and Communication: Health promotion glossary. In. Geneve: World Health Organization; 1998: 36.

7. Wood W, Eagly AH: A cross-cultural analysis of the behavior of women and men: implications for the origins of sex differences. Psychological bulletin 2002, 128(5):699-727.

8. Santelli J, Ott MA, Lyon M, Rogers J, Summers D, Schleifer R: Abstinence and abstinence-only education: A review of U.S. policies and programs. Journal of Adolescent Health 2006, 38(1):72-81.

9. Kritsotakis G, Psarrou M, Vassilaki M, Androulaki Z, Philalithis AE: Gender differences in the prevalence and clustering of multiple health risk behaviours in young adults. Journal of Advanced Nursing 2016, 72(9):2098-2113.

10. Lechner KE, Garcia CM, Frerich EA, Lust K, Eisenberg ME: College students' sexual health: personal responsibility or the responsibility of the college? Journal of American college health : J of ACH 2013, 61(1):28-35.

11. Programa Nacional para a infeção VIH/SIDA: Infeção VIH e SIDA - Desafios e Estratégias 2018. In., Direção-Geral da Saúde edn: Direção-Geral da Saúde; 2018.

12. Kirby D: The impact of schools and school programs upon adolescent sexual behavior. The Journal of Sex Research 2002, 39(1):27-33.

13. Matos MGd, Reis M, Ramiro L: Saúde sexual e reprodutiva dos estudantes do ensino superior. In. Edited by Aventura Social. http://aventurasocial.com/arquivo/1303148036_Relatorio_HBSC_SSREU.pdf 2011: 154.

14. Nobre PJ, Pinto-Gouveia J: Questionnaire of cognitive schema activation in sexual context: a measure to assess cognitive schemas activated in unsuccessful sexual situations. J Sex Res 2009, 46(5):425-437.

15. Kirby DB, Laris BA, Rolleri LA: Sex and HIV Education Programs: Their Impact on Sexual Behaviors of Young People Throughout the World. Journal of Adolescent Health 2007, 40(3):206-217.

16. Fisher JD, Fisher WA: Changing AIDS-risk behavior. Psychological bulletin 1992, 111(3):455.

17. Fisher JD, Fisher WA, Bryan AD, Misovich SJ: Information-motivation-behavioral skills model-based HIV risk behavior change intervention for inner-city high school youth. Health psychology : official journal of the Division of Health Psychology, American Psychological Association 2002, 21(2):177186.

18. Nutbeam D: Health literacy as a public health goal: a challenge for contemporary health education and communication strategies into the 21 st century. Health Promotion International 2000, 15(3):259267. 
19. Kirby JLM, van der Sluijs W, Currie C: Attitudes towards condom use among young people. In: HBSC Briefing Paper. Edinburgh: Health Behaviour in School-Aged Children;; 2010: 4.

20. Weinstein RB, Walsh JL, Ward LM: Testing a New Measure of Sexual Health Knowledge and Its Connections to Students' Sex Education, Communication, Confidence, and Condom Use. International Journal of Sexual Health 2008, 20(3):212-221.

21. Berten H, Van Rossem R: Doing worse but knowing better: an exploration of the relationship between HIV/AIDS knowledge and sexual behavior among adolescents in Flemish secondary schools. Journal of adolescence 2009, 32(5):1303-1319.

22. Glanz K, Rimer BK, Viswanath K: Health behavior and health education : theory, research, and practice. San Francisco, CA: Jossey-Bass; 2008.

23. Frank E, Coughlin SS, Elon L: Sex-Related Knowledge, Attitudes, and Behaviors of U.S. Medical Students. Obstetrics \& Gynecology 2008, 112(2):311-319.

24. Fayers T: Medical student awareness of sexual health is poor. International Journal of STD \& AIDS 2003, 14(6):386-389.

25. Warner C, Carlson S, Crichlow R, Ross MW: Sexual Health Knowledge of U.S. Medical Students: A National Survey. The Journal of Sexual Medicine 2018, 15(8):1093-1102.

26. Rodriguez M: Teaching Our Teachers To Teach: A SIECUS Study On Training and Preparation for HIV/AIDS Prevention and Sexuality Education. SIECUS Report 1995, 28(2).

27. Arnett JJ: Emerging adulthood: A theory of development from the late teens through the twenties. American Psychologist 2000, 55(5):469-480.

28. Silva CF, Rocha P, Santos P: Consumption of licit and illicit substances in Portuguese young people: a population-based cross-sectional study. Journal of International Medical Research 2018, 46(8):3042-3052.

29. Deardorff J, Gonzales NA, Christopher FS, Roosa MW, Millsap RE: Early puberty and adolescent pregnancy: the influence of alcohol use. Pediatrics 2005, 116(6):1451-1456.

30. Omoteso BA: A Study of the Sexual Behaviour of University Undergraduate Students in Southwestern Nigeria. Journal of Social Sciences 2006, 12(2):129-133.

31. Biglan A, Metzler CW, Wirt R, Ary D, Noell J, Ochs L, French C, Hood D: Social and behavioral factors associated with high-risk sexual behavior among adolescents. Journal of Behavioral Medicine 1990, 13(3):245-261.

32. Kirby DB, Baumler E, Coyle KK, Basen-Engquist K, Parcel GS, Harrist R, Banspach SW: The "Safer Choices” Intervention: Its Impact on the Sexual Behaviors of Different Subgroups of High School Students. Journal of Adolescent Health 2004, 35(6):442-452.

33. Aggleton P, Campbell C: Working with young people - towards an agenda for sexual health. Sexual and Relationship Therapy 2000, 15(3):283-296.

34. De Meyer S, Jaruseviciene L, Zaborskis A, Decat P, Vega B, Cordova K, Temmerman M, Degomme O, Michielsen K: A cross-sectional study on attitudes toward gender equality, sexual behavior, positive 
sexual experiences, and communication about sex among sexually active and non-sexually active adolescents in Bolivia and Ecuador. Global health action 2014, 7:24089.

35. Fisher TD: Sex of Experimenter and Social Norm Effects on Reports of Sexual Behavior in Young Men and Women. Archives of Sexual Behavior 2007, 36(1):89-100.

36. Ramiro-Sanchez T, Ramiro MT, Bermudez MP, Buela-Casal G: Sexism and sexual risk behavior in adolescents: Gender differences. International journal of clinical and health psychology : IJCHP 2018, 18(3):245-253.

37. Buss DM, Schmitt DP: Sexual Strategies Theory: An Evolutionary Perspective on Human Mating. Psychological Review 1993, 100(2):204-232.

38. Buss DM: Sexual Strategies Theory: Historical Origins and Current Status. Journal of Sex Research 1998, 35(1):19-31.

39. Eagly AH, Wood W: The origins of sex differences in human behavior - Evolved dispositions versus social roles. American Psychologist 1999, 54(6):408-423.

40. Crawford M, Popp D: Sexual double standards: A review and methodological critique of two decades of research. The Journal of Sex Research 2003, 40(1):13-26.

41. Fasula AM, Carry M, Miller KS: A multidimensional framework for the meanings of the sexual double standard and its application for the sexual health of young black women in the U.S. J Sex Res 2014, 51(2):170-183.

42. Tolman DL: Doing desire: Adolescent girls' struggles for/with sexuality. Gender \& Society 1994, 8(3):324-342.

43. Brewster KL, Cooksey EC, Guilkey DK, Rindfuss RR: The changing impact of religion on the sexual and contraceptive behavior of adolescent women in the United States. Journal of Marriage and the Family 1998:493-504.

44. Kann L, McManus T, Harris WA, Shanklin SL, Flint KH, Queen B, Lowry R, Chyen D, Whittle L, Thornton $\mathrm{J}$ et al: Youth Risk Behavior Surveillance - United States, 2017. Morbidity and mortality weekly report Surveillance summaries (Washington, DC : 2002) 2018, 67(8):1-114.

45. Darroch JE, Landry DJ, Singh S: Changing emphases in sexuality education in U.S. public secondary schools, 1988-1999. Family planning perspectives 2000, 32(5):204-211, 265.

46. Lansford JE, Dodge KA, Pettit GS, Bates JE: A Public Health Perspective on School Dropout and Adult Outcomes: A Prospective Study of Risk and Protective Factors From Age 5 to 27 Years. Journal of Adolescent Health 2016, 58(6):652-658.

47. Saraçoğlu GV, Erdem I, Doğan S, Tokuç B: Youth Sexual Health: Sexual Knowledge, Attitudes, and Behavior Among Students at a University in Turkey. Noro psikiyatri arsivi 2014, 51(3):222-228.

\section{Tables}




\begin{tabular}{|c|c|c|c|c|}
\hline \multicolumn{2}{|l|}{ Gender } & $\begin{array}{l}\text { Male } \\
298(26.3 \%)\end{array}$ & $\begin{array}{l}\text { Female } \\
833(73.7 \%)\end{array}$ & $\begin{array}{l}\text { Total } \\
1131\end{array}$ \\
\hline \multicolumn{2}{|l|}{ Mean Age (SD) } & $21.8( \pm 3.0)$ & $21.5( \pm 3.0)$ & $21.6( \pm 3.0)$ \\
\hline Nationality & $\begin{array}{l}\text { Portuguese } \\
\text { CPLC * } \\
\text { Other } \\
\text { No answer }\end{array}$ & $\begin{array}{l}283(95 \%) \\
13(4.4 \%) \\
2(0.6 \%) \\
0(0 \%)\end{array}$ & $\begin{array}{l}790(95.1 \%) \\
32(3.9 \%) \\
9(1 \%) \\
2(0.2 \%)\end{array}$ & $\begin{array}{l}1073(95 \%) \\
45(4 \%) \\
10(1 \%) \\
2(0.2 \%)\end{array}$ \\
\hline Habitational Zone & $\begin{array}{l}\text { Rural } \\
\text { Suburban (<70 000 inhabitants) } \\
\text { Urban (>70 000 inhabitants) } \\
\text { No answer }\end{array}$ & $\begin{array}{l}53(17.8 \%) \\
115(38.6 \%) \\
130(43.6 \%) \\
0(0 \%)\end{array}$ & $\begin{array}{l}193(23.2 \%) \\
311(37.4 \%) \\
328(39.4 \%) \\
1(0.1 \%)\end{array}$ & $\begin{array}{l}246(21.7 \%) \\
426(37.8 \%) \\
458(40.5 \%) \\
1(0.09 \%)\end{array}$ \\
\hline Socioeconomic status ** & $\begin{array}{l}\text { Upper } \\
\text { Upper middle } \\
\text { Middle } \\
\text { Lower middle } \\
\text { Lower } \\
\text { No answer }\end{array}$ & $\begin{array}{l}132(44.4 \%) \\
93(31.3 \%) \\
67(22.6 \%) \\
4(1.3 \%) \\
1(0.3 \%) \\
1(0.3 \%)\end{array}$ & $\begin{array}{l}267(32.1 \%) \\
371(44.7 \%) \\
167(20.1 \%) \\
26(3.1 \%) \\
0(0 \%) \\
2(0.2 \%)\end{array}$ & $\begin{array}{l}399(35.4 \%) \\
464(41.1 \%) \\
234(20.7 \%) \\
30(2.7 \%) \\
1(0.09 \%) \\
2(0.2 \%)\end{array}$ \\
\hline Schooling & $\begin{array}{l}\text { Bachelor } \\
\text { Integrated Master } \\
\text { Other } \\
\text { No answer }\end{array}$ & $\begin{array}{l}160(53.9 \%) \\
127(42.8 \%) \\
10(3.3 \%) \\
1(0.3 \%)\end{array}$ & $\begin{array}{l}490(59 \%) \\
291(35 \%) \\
50(6 \%) \\
2(0.2 \%)\end{array}$ & $\begin{array}{l}650(57.6 \%) \\
418(37,1 \%) \\
60(5,4 \%) \\
2(0.2 \%)\end{array}$ \\
\hline Study course & $\begin{array}{l}\text { Health-related degree } \\
\text { Other degree } \\
\text { No answer }\end{array}$ & $\begin{array}{l}156(52.3 \%) \\
142(47.7 \%) \\
0(0 \%)\end{array}$ & $\begin{array}{l}466(56 \%) \\
367(44 \%) \\
0(0 \%)\end{array}$ & $\begin{array}{l}622(55 \%) \\
509(45 \%) \\
0(0 \%)\end{array}$ \\
\hline Spirituality & $\begin{array}{l}\text { Atheist } \\
\text { Personal God } \\
\text { Living force/spirit } \\
\text { Without formal opinion } \\
\text { No answer }\end{array}$ & $\begin{array}{l}92(31.3 \%) \\
59(20.1 \%) \\
65(22.1 \%) \\
78(26,5 \%) \\
4(1.3 \%)\end{array}$ & $\begin{array}{l}152(18.4 \%) \\
203(24.5 \%) \\
217(26.2 \%) \\
255(30.8 \%) \\
6(0.72 \%)\end{array}$ & $\begin{array}{l}244(21,8 \%) \\
262(23,4) \\
282(25,1 \%) \\
333(29,7 \%) \\
10(0.9 \%)\end{array}$ \\
\hline Sexual orientation & $\begin{array}{l}\text { Heterosexual } \\
\text { Homosexual } \\
\text { Bisexual } \\
\text { No answer }\end{array}$ & $\begin{array}{l}193(68.7 \%) \\
67(23.8 \%) \\
21(7.5 \%) \\
17(5.7 \%)\end{array}$ & $\begin{array}{l}639(80 \%) \\
101(12.6 \%) \\
59(7.4 \%) \\
34(4.1 \%)\end{array}$ & $\begin{array}{l}832(77.0 \%) \\
168(15,6 \%) \\
80(7,4 \%) \\
51(4.5 \%)\end{array}$ \\
\hline Sexual Activity & $\begin{array}{l}\text { Yes } \\
\text { No } \\
\text { No answer }\end{array}$ & $\begin{array}{l}268(90.2 \%) \\
29(9.8 \%) \\
0(0 \%)\end{array}$ & $\begin{array}{l}761(91.7 \%) \\
69(8.3 \%) \\
0(0 \%)\end{array}$ & $\begin{array}{l}1029(91.3 \%) \\
98(8.7 \%) \\
0(0 \%)\end{array}$ \\
\hline Sexual Education & \begin{tabular}{|l|} 
Yes \\
No \\
No answer
\end{tabular} & $\begin{array}{l}217(72.8 \%) \\
81(27.2 \%) \\
0(0 \%)\end{array}$ & $\begin{array}{l}623(74.8 \%) \\
210(25.2 \%) \\
0(0 \%)\end{array}$ & $\begin{array}{l}840(74,3 \%) \\
291(25,7 \%) \\
0(0 \%)\end{array}$ \\
\hline
\end{tabular}


* CPLC - community of Portuguese language countries, ** Socioeconomic status based on Graffar Index

\section{Figures}
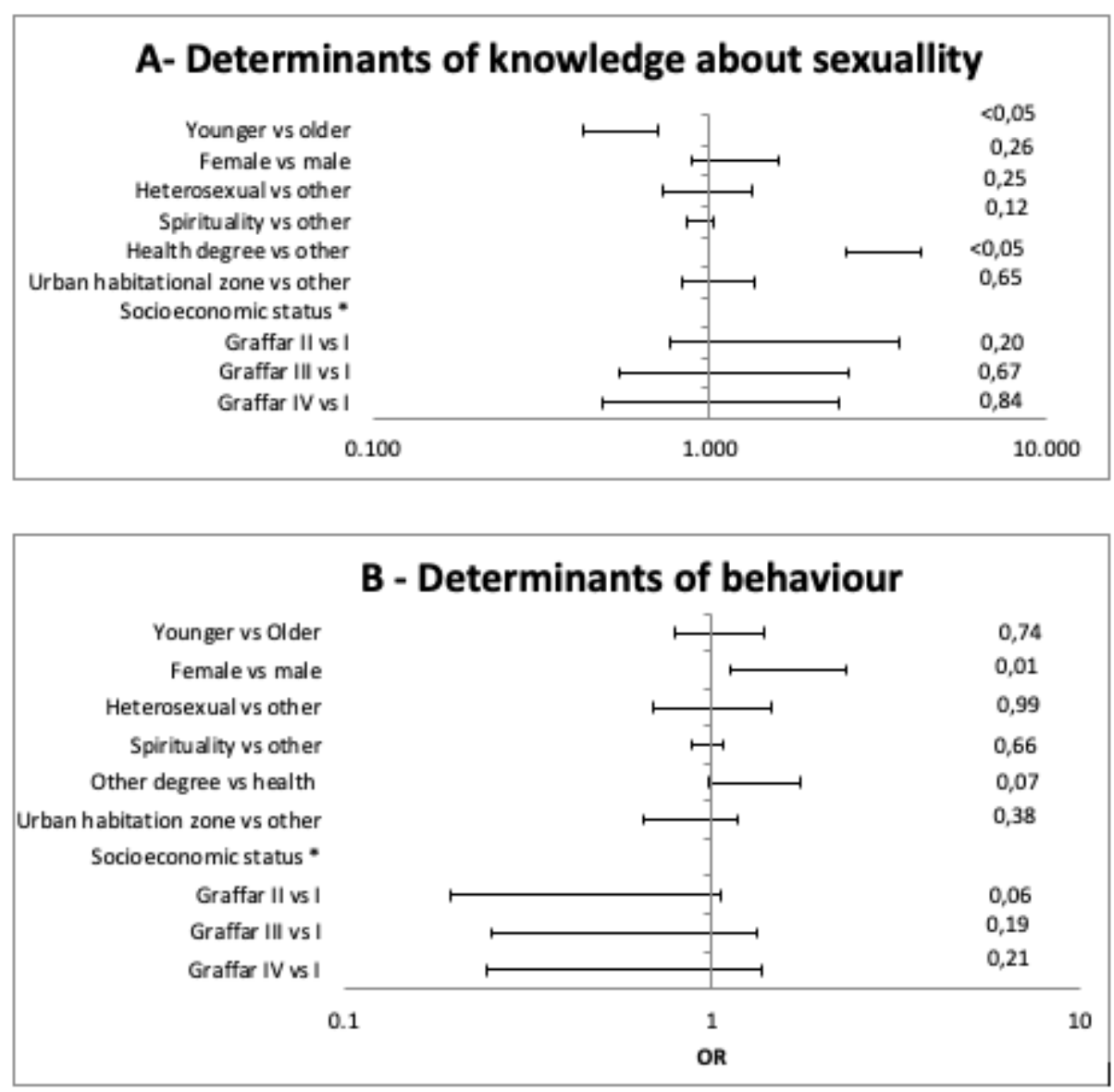

* Socioeconomic characterization is based on Graffar Index

\section{Figure 1}

Influence of sociodemographic factors in knowledge (A) and behaviors (B) about sexual issues in university students. 


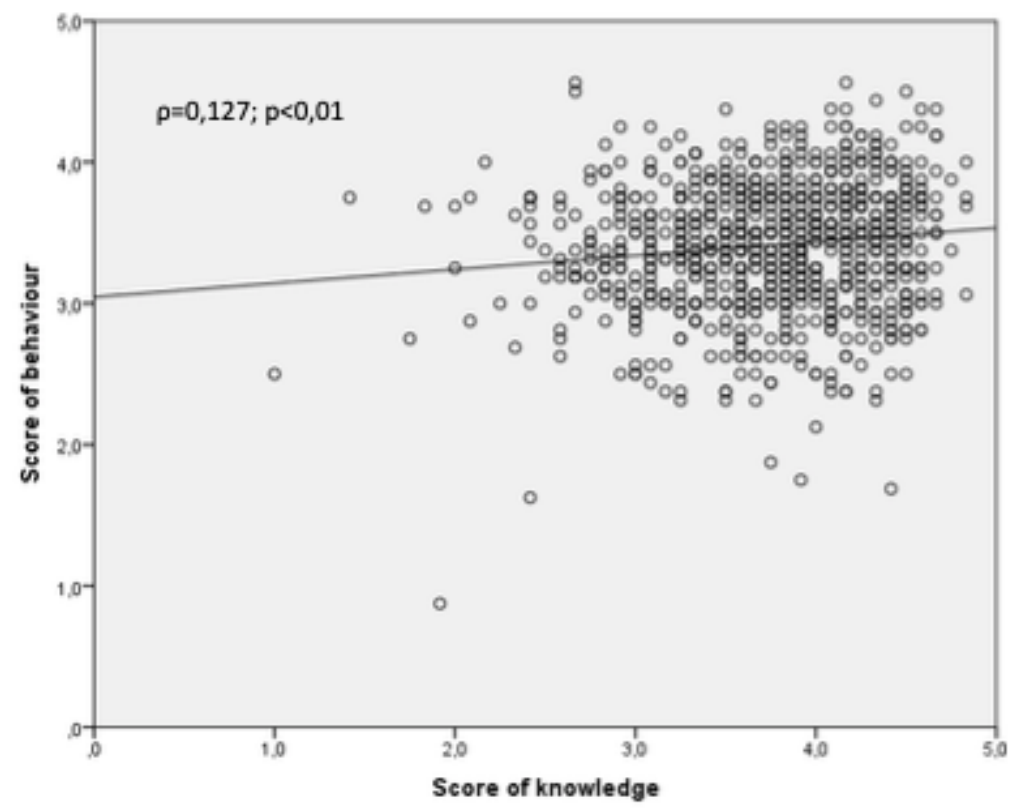

Figure 2

Relationship between knowledge and sexual behavior 